Música, cultura negra e formação de professores: refletindo sobre as

leis $n^{\circ} 11.769 / 2008$ e 10.639/2003

\title{
Renan Santiago
}

Ana Ivenicki 
Este trabalho apresenta três objetivos principais: (i) mostrar como as Leis $\mathrm{n}^{\circ} 11.769 / 2008$ e 10.639/2003 estão concatenadas e, por tal razão, devem ser pensadas em conjunto; (ii) apontar os espaços que a cultura negra tem encontrado no currículo da formação de professores de Música; e (iii) analisar esses espaços, auxiliando, assim, as reflexões sobre como a cultura e a música negra podem estar presentes nos currículos das Licenciaturas em Música, a fim de que estas formem professores competentes para trabalhar também com a cultura e a musicalidade negras. Para tal, este trabalho analisou as grades curriculares das principais instituições que oferecem o curso de Licenciatura em Música na cidade do Rio de Janeiro e concluiu que se faz necessário um repensar das Licenciaturas em Música, em uma perspectiva multicultural, que buscará descontruir as hierarquias culturais geradas pela colonização, promovendo a igualdade nos saberes e a desmarginalização da identidade cultural negra.

Palavras-chave: Ensino de Música; Formação de professores; Multiculturalismo.

\section{Introdução}

Z ducação Musical não é uma novidade no ensino básico no CBrasil. Sobreira (2012) disserta que a Música foi instituída como componente curricular pela primeira vez ainda no Período Colonial, em 1549, pelo padre Manoel da Nóbrega, e até 1931, outras leis que incluíam a Música ${ }^{1}$ na Educação pública foram sancionadas, mas estas não possuíam abrangência nacional. Porém, na Era Vargas, por meio do Decreto no. 24.794/1934, o ensino do Canto Orfeônico passou a ser obrigatório na Educação pública em nível nacional. Esse projeto, coordenado diretamente pelo compositor e regente Heitor Villa-Lobos, pretendia trabalhar os conceitos musicais por meio do Canto Orfeônico e, por ter um caráter cívico, disciplinador e nacionalista, teve o total apoio do governo Vargas.

Com o declínio do Estado Novo, o projeto do Canto Orfeônico perdeu muita força. A autora supracitada afirma que o ensino de

${ }^{1}$ No presente trabalho, utilizamos o vocábulo "Música" escrito com letra inicial maiúscula para expressar uma ciência e uma disciplina escolar (ex. "A Música na escola ainda não é uma realidade em todos os municípios do Brasil”); e o vocábulo "música" escrito com letra inicial minúscula como sinônimo de composiçáo musical ou prática social (ex. "A música negra precisa ser mais valorizada"). 
Música - sendo ora denominado por Canto Orfeônico, ora por Educação Musical - continuou a existir nas escolas, mas de forma bem menos significativa, e uma queda mais brusca de sua presença nos currículos escolares ocorreu com a implementação da Lei n. 5.692/71, que substituiu a disciplina de Educação Musical pela disciplina de Educação Artística que, além da Música, também era composta pelo ensino de Teatro e Artes Plásticas.

A Lei no 5.692/71 não retirou por completo a Música dos currículos escolares, apenas possibilitou que outras manifestaçóes artísticas também pudessem ser ensinadas nas salas de aula. Portanto, essa substituição não deve ser entendida com sentido de extirpação, de eliminação. De qualquer forma, a Música perdeu a hegemonia que tinha entre as manifestaçóes artísticas no currículo escolar e muito do espaço e do poder que tinha na Educação Básica.

Com a promulgação da Lei de Diretrizes e Bases da Educação Nacional de 1996 (LDBN/96) e por pressôes de entidades públicas, sobretudo da Associação Brasileira de Educação Musical (ABEM), foi decretada a Lei no 11.769/2008 (BRASIL, 2008), que impóe que o conteúdo "Música" seja obrigatório na Educação Básica, o que traz à tona novamente um grande processo do ensino de Música na Educação Básica brasileira, que se pode dizer ser bem maior do que o projeto que Villa-Lobos estabelecera e traz consigo outras problemáticas. Sobre isso, Sobreira (2012, p. 76) afirma que:

Sem desconsiderar que a população daquela época [aqui se referindo à época do projeto de Canto Orfeônico] era majoritariamente rural, sendo que 'mais de $75 \%$ dos habitantes não tinha acesso à educação formal' [...], penso que a comparação não deve ser feita em termos quantitativos, mas levando em consideração o intuito de ampliar o ensino de Música para uma maioria que não frequentava os conservatórios e também na defesa da obrigatoriedade desse ensino. A empreitada dos tempos atuais é maior, não só pelo aumento da população escolarizada como pela ampliação da obrigatoriedade para todas as escolas, inclusive as da rede privada. Além disto, do ponto de vista ideológico, é imensa a tarefa de introduzir uma matéria que náo contribui para o mundo do trabalho e da competitividade presumida pelas políticas educacionais que vigoram a partir dos anos 1990 . 
Dessa forma, a Lei no 11.769/2008 trouxe uma série de expectativas, preocupaçóes e até utopias entre professores da Educação Básica e pesquisadores. Dentro dessa perspectiva de um novo e grande movimento de Educação Musical que tem emergido em nosso país, este artigo busca contribuir com a discussão, concatenando a lei citada com a Lei $\mathrm{n}^{\circ} 10.639 / 2003$, que modificou a LDBN/96 (BRASIL, 1996), tornando os ensinos da História e Cultura Afro-Brasileira e Africana obrigatórios para a Educação Básica (BRASIL, 2003).

Essas duas leis mantêm uma relação intrínseca, pois o segundo parágrafo do primeiro artigo da Lei n. 10.639/2003 disserta que "os conteúdos referentes à História e Cultura Afro-Brasileira serão ministrados no âmbito de todo o currículo escolar, em especial nas áreas de Educaçáo Artística e de Literatura e História Brasileiras" (BRASIL, 2003 - grifo nosso). Embora a expressão Educação Artística já seja ultrapassada, cabe observar que a referida Lei traz implícito que o ensino da Música deve também contemplar os conhecimentos e a cultura musical de matriz africana.

A Lei $\mathrm{n}^{\circ} 10.639 / 2003$ foi sabiamente modificada pela Lei 11.645/2008 e passou a incluir também a Cultura e História indígena na sua formulação. O presente artigo, por ter como objeto de estudo os principais cursos de Licenciatura em Música da cidade do Rio de Janeiro, delimitou-se em analisar somente os espaços que a cultura negra tem encontrado no currículo das Licenciaturas em Música pelo fato de que, nas práticas culturais e musicais da cidade em questáo, tal cultura já tem espaços consolidados e compóe parte da identidade cultural de boa parte do alunado da Educação Básica.

Mas isso não significa que a musicalidade indígena não tenha importância e que não deva ser também incorporada ao currículo da Educação Básica e da formação de professores de Música. Portanto, será importante, em futuros estudos, considerar também a música e a cultura indígena pela necessidade que ambas têm em ganhar visibilidade e consistência nos documentos curriculares e, sobretudo, nas práticas reais de sala de aula.

Um grande desafio para o cumprimento da Lei no 10.639/2003 na Educação Musical é a formação de professores, pois, evidentemente, o professor de Música que tiver em sua formação conteúdos voltados para a diversidade cultural, incluindo nisso culturas e conhecimentos afro-brasileiros, terá melhores condições de trabalhar temáticas 
relativas à história e à cultura afro-brasileira. É sabido, também, que a conduta do professor na sala de aula está diretamente relacionada com o que este aprende em sua formação inicial, ou seja, no curso de Licenciatura em Música. Portanto, não é suficiente apenas pesquisar o que está sendo feito de concreto nas aulas de Música da Educação Básica, mas também se faz necessário pesquisar e refletir sobre a formação do professor de Música. Como ele está sendo formado? Com qual currículo? Com quais disciplinas? Sua formação o tornará sensível à diversidade cultural corriqueiramente encontrada nas salas de aula?

Longe de responder a todas essas perguntas, este estudo busca contribuir com a discussão em questão, tendo como objetivo explicitar a urgência de refletir sobre a importância de pensar a formação de professores de Música para que as Leis no 11.769 e 10.639 atuem em conjunto em prol de uma Educação Musical voltada para a diversidade cultural. Sendo assim, há a necessidade de pensarmos em formação de professores que leve em consideração também as questóes culturais, o que poderá tornar os professores em formação capazes de atuar, dentre outros aspectos, com as culturas africana e afro-brasileira, expondo criticamente a temática das relaçóes étnico-raciais e reduzindo, assim, preconceitos, discriminações e violências simbólicas.

\section{Licenciatura em Música: currículo e relações de poder}

$\mathrm{O}$ conceito de neutralidade da Educação foi superado já há bastante tempo e, atualmente, os debates sobre currículo e prática educativa estão permeados pelas discussóes sobre as relaçóes e disputas de poder. Nem a escola nem a Educação são neutras; antes, expressam interesses, seja de grupos dominantes que buscam reafirmar seu poder, seja de grupos dominados que buscam resistir às imposiçóes culturais que silenciam suas vozes e marginalizam suas açóes (SILVA, 2009).

O currículo escolar é a materialidade dessas disputas de poder. Esse documento não somente expressa uma seleção de conhecimentos que foram classificados como úteis ou dignos de serem passados adiante para as futuras geraçóes, mas também é um instrumento utilizado por grupos sociais a fim de forjar identidades, construir barreiras culturais, demarcar territórios e hierarquizar culturas. Mas, em contrapartida, pode também ser um instrumento de resistência, de militância, de 
reivindicação de espaços (SILVA, 2009).

Portanto, o currículo escolar nos dias atuais deve se adequar à multiculturalidade característica da nossa sociedade e das nossas escolas, e um primeiro passo a ser dado nessa direção é negar a hegemonia cultural dos currículos, pois o monoculturalismo, expresso principalmente por meio do eurocentrismo, silencia as vozes dos diversos grupos culturais que convivem na escola cotidianamente.

No meio de toda essa discussão, encontra-se a Educação Musical que, infelizmente, não tem se posicionado de modo crítico o suficiente em relação à diversidade cultural. Lazzarin (2008, p. 124) critica a despolitização da disciplina de Música:

A educação musical, como área de produção e de transmissão do conhecimento, em alguns momentos, parece desconsiderar que está inserida em um movimento de cultura que é maior que o simples ensino de música. Em outras palavras, parece ocorrer uma despolitização no sentido específico das relaçóes entre saber e poder [...]. O que eu quero dizer é que, preocupada em apresentar soluçóes e respostas aos problemas formativos, a pedagogia superficializa ou esconde o próprio conflito de lidar com conflitos.

Dessa forma, esse novo ressurgir da Educação Musical na Educação Básica, se não for ministrado de forma crítica, pode correr o risco de corroborar para a existência de um ensino eurocêntrico que subvaloriza os conhecimentos populares e a cultura afro-brasileira, incluindo nisso a sua musicalidade.

Não há a intenção de argumentar que não existe a possibilidade de atuar com as influências europeias da Educação Musical nas aulas de Música, pois os fundamentos teóricos do ensino de Música advêm, em sua maioria, de educadores musicais europeus, como Dalcroze, Kodály e Williams. Tais metodologias devem ser relacionadas com a realidade do educando, visto que foram desenvolvidas tendo como alvo um alunado proveniente de outras culturas e de outras épocas, ou seja, são necessárias ressignificaçôes para as diferentes realidades brasileiras. Por outro lado, não basta simplesmente incluir um repertório de raiz africana nas aulas, mas sim tornar essa cultura e a

${ }^{2}$ Segundo Stuart Hall (2003), a convivência de diversos grupos culturais em um mesmo ambiente social é definida como multiculturalidade. 
cultura popular em geral como formas de conhecimento mais amplas, problematizadas e discutidas.

É notório que conhecimentos de grupos historicamente marginalizados e oprimidos, como os negros, têm pouco espaço nos currículos escolares. Dessa forma, esses grupos têm suas vozes silenciadas por não serem representados em tais currículos, e os estereótipos e marcaçóes historicamente produzidas continuam sendo produzidas e reproduzidas (CANEN; MOREIRA, 2001).

A Lei $n^{\circ} 10.639$, ao propor uma modificação curricular em favor de um grupo que busca maior reconhecimento da sua cultura, também expressa relaçóes de poder, pois essa Lei se deu por pressóes de movimentos sociais que percebiam que, a despeito de grande parte da população brasileira ser afrodescendente, havia poucos conteúdos nos livros didáticos e nos currículos voltados para a cultura afro-brasileira. Porém, também não se pode ignorar a influência neoliberal por detrás da aprovação da Lei, pois é sabido que o descontentamento social prejudica os negócios e, em alguns casos, o governo neoliberal, por meio de legislaçóes específicas e de ações afirmativas, precisa aliviar a pobreza e diminuir as insatisfaçóes sociais (LEHER, 2005).

A partir da temática proposta pela Lei no 10.639 , levamos a discussão para o campo da formação de professores de Música. Souza (2012) afirma que as questóes condizentes às relaçóes étnico-raciais devem também estar presentes na formação de professores - inclusive a continuada -, com o propósito de formar profissionais capazes de não apenas trabalhar com conteúdos provenientes da cultura negra de forma descontextualizada, mas também de abordarem tal temática continuamente e contextualizadamente, com o objetivo de desconstruir possíveis estereótipos e imagens negativas de negros, além de identificar as diversas formas de preconceito que podem ocorrer no cotidiano escolar e intervir positivamente nesses casos. Isso propiciará aos estudantes da Educaçáo Básica um panorama geral da cultura africana e afro-brasileira, bem como um conhecimento sobre a situaçáo dos negros na sociedade brasileira, nas sociedades africanas e no restante do mundo.

Em contrapartida o que, em geral, é observado nas instituiçóes de ensino superior que formam professores de Música é um ensino conservatorial, termo usado para definir o ensino tradicional de Música. Tal forma de ensino caracteriza-se, dentre outros aspectos, por 
valorizar a música erudita e subvalorizar outros tipos de manifestaçôes musicais, como a música popular, a música midiática e a música afrobrasileira e africana (SANTOS, 2012).

Pereira (2014), embasado em vários outros autores, assinala que os cursos superiores de Música, incluindo as Licenciaturas, estão atravessados por um habitus conservatorial, ou seja, tendem a ter o ensino conservatorial como uma estrutura estruturante ${ }^{3}$ de suas práticas, estando nisso também incluso seus projetos políticopedagógicos e currículos ${ }^{4}$. Nesse sentido, as Licenciaturas em Música, de forma geral, conservam um caráter colonizador, que desvaloriza as práticas musicais de vários grupos populares, incluindo nisso os afrobrasileiros. Evidentemente, os cursos de Licenciatura em Música no Brasil são numerosos e diferentes (PIRES, 2003; MATEIRO, 2009) e, obviamente, formas de resistência podem ser encontradas, mas não se pode negar que o habitus conservatorial perpassa por muitas das nossas licenciaturas.

É interessante notar que certos estilos musicais de raiz negra, como o choro, o jazz e o blues, são bem aceitos e incorporados nos currículos das faculdades de Música, mas sem contradizer a lógica do habitus conservatorial. Isso só ocorre porque tais práticas musicais foram "eruditizadas", ou seja, eram tidas como musicalidades inferiores, mas, com o passar do tempo, foram incorporadas pelos padróes culturais elitizados e, com isso, ganharam espaço na academia, mas, em compensação, perderam o status de musicalidade que representa os negros. Essa forma de "branqueamento cultural" não é observada em outras musicalidades de matriz negra, como o funk, o rap, o pagode ou o hip-hop, o que marginaliza tais musicalidades, afastando-as dos currículos dos cursos superiores de Música e, possivelmente, das salas de aula.

Um grande problema por detrás desses fatos é que tais musicalidades marginalizadas são aquelas preferidas por muitos jovens, educandos do ensino público, principalmente aqueles pertencentes às camadas populares. Ora, quando certo grupo social ou grupos sociais impóem a sua cultura a outros grupos, desprovendo-os das suas

${ }^{4}$ Termo cunhado por Pierre Bourdieu para definir seu conceito de habitus. Ver: BOURDIEU, Pierre. Estrutura, Habitus e Prática. In: A economia das trocas simbólicas. Trad. Sérgio Miceli. 3. ed. São Paulo: Perspectiva, 1992, p. 337-361.

${ }^{5}$ Outros trabalhos, como Vieira (2000), Greif (2006, 2007) e Almeida (2009) também enfatizam a existência de um caráter conservador no ensino superior de Música, incluindo a formação de professores. 
próprias identidades culturais, estabelece-se uma convivência violenta no que tange aos aspectos simbólicos, sendo esse fenômeno conhecido como violência simbólica (BOURDIEU; PASSERON, 2011, p. 19).

Pretendemos argumentar que, se a cultura e a musicalidade negras forem desprezadas nas salas de aula, muitos educandos não se sentirão representados com o repertório das aulas de Música, o que poderá ocasionar problemas de motivação e aprendizagem ${ }^{6}$.

\section{Licenciatura em Música: analisando a grade}

A promulgação da Lei no 10.639/2003, sem dúvida, foi um Agrande passo dado na direção da melhoria da situação de vida dos afro-brasileiros, mas não é suficiente para garantir que a musicalidade negra esteja presente nas salas de aula, pois é necessário que as instituiçóes de ensino superior também busquem se adequar à Lei em questão. $\mathrm{O}$ presente artigo, delimitando seu objeto de pesquisa na cidade do Rio de Janeiro e buscando entender se a Lei 10.639 influenciou reformas curriculares nos cursos de Licenciatura em Música, analisou as grades curriculares das três instituiçôes mais reconhecidas no ensino superior de Música desta cidade, que são também aquelas que têm o maior número de alunos - Universidade Federal do Rio de Janeiro (UFRJ), Universidade Federal do Estado do Rio de Janeiro (UNIRIO) e Conservatório Brasileiro de Música - Centro Universitário (CBM-CEU).

A análise das grades curriculares presentes nos Projetos PolíticoPedagógicos dos cursos de Licenciatura em Música da UFRJ (2006) e da UNIRIO (2008) nos possibilita concluir que nenhuma disciplina específica para tratar da temática da Lei no 10.639 foi criada desde a sua promulgação. Já a análise do Projeto Político-Pedagógico do CBMCEU (2011), instituição particular deveras reconhecida na cidade do Rio de Janeiro, revela que a grade curricular foi modificada em 2011 oito anos após a promulgação da lei -, e todos os alunos dos cursos de Bacharelado e Licenciatura em Música passaram a assistir à disciplina de História e Cultura Afro-brasileira, que é oferecida em regime

\footnotetext{
${ }^{6}$ Pierre Bourdieu, por meio do conceito de capital cultural, afirma que o currículo escolar carente de conteúdos que fazem parte da vivência extraclasse e dos interesses de certo indivíduo ou grupo social é um dos fatos responsáveis pela falta de motivação, fracasso e evasão escolar. Ver: BOURDIEU, Pierre. Os três estados do capital cultural. In: NOGUEIRA, Maria Alice; CATANI, Afrânio (Org.). Escritos de educação. 10. ed. Petrópolis. Vozes, 2008. p.71-79.
} 
obrigatório. Ademais, foi criado, em 2013, o curso de pós-graduação latu sensu intitulado "História e Cultura Afro-Brasileira". Mesmo antes da Lei no 10.639, a instituição já oferecia como obrigatória a disciplina de História da Música Popular Brasileira que, dentre outras intençóes, discute a contribuição dos negros na Música brasileira. A UNIRIO também oferece tal disciplina como obrigatória, mas, na UFRJ, essa disciplina é optativa.

Pode-se dizer que a Lei no 10.639 provocou mudanças significativas na organização curricular do CBM-CEU, mas vale ressaltar que a UFRJ e a UNIRIO oferecem outras disciplinas que podem - ou não - ministrar conteúdos relativos às questôes étnicoraciais e que não estão presentes na grade do CBM-CEU, como a disciplina de Educação e Sociologia e a disciplina de Currículo. É importante também salientar que ambas as Faculdades de Educação da UFRJ $^{7}$ e da UNIRIO ${ }^{8}$ oferecem disciplinas optativas que discutem a temática das relaçóes étnico-raciais que podem ser assistidas pelos alunos de Música, porém estas não contam créditos para tais alunos. O CBM-CEU não oferece quaisquer disciplinas optativas.

O fato de haver poucas disciplinas voltadas para as relaçóes étnico-raciais nas grades curriculares analisadas, de certa forma, confirma o que foi enunciado por Canen (2011), que afirma que a sensibilização na formação de professores em relação às questôes multiculturais - estando inclusas as questóes étnico-raciais - se dá, geralmente, em ambientes fora da sala de aula ou em projetos extracurriculares, como em cine-debates. Isso demonstra a relação de poder presente nos currículos, que deixa de fora conhecimentos de grupos com menos poder institucional.

Projetos extracurriculares podem exprimir formas de resistência a currículos engessados e monoculturais e podem contribuir com futuras reformulaçóes curriculares e com adiçóes de disciplinas específicas, porém, se as discussóes sobre as relaçôes étnico-raciais se

${ }^{7}$ A UFRJ oferece as seguintes disciplinas como optativas que tratam direta ou indiretamente das questóes étnico-raciais: Intelectuais negras; Multiculturalismo e educação; Colonidade, Educação e Pedagogia da Revolução. Disponível em https://siga.ufrj.br/sira/temas/zire/frameConsultas.jsp? mainPage=/repositoriocurriculo/B137164D-92A4-F79F-3C28-DD379D8B0991.html. Acessado em 29/06/2015.

${ }^{8}$ A UNIRIO oferece as seguintes disciplinas como optativas que tratam direta ou indiretamente das questôes étnico-raciais: Cotidiano escolar e diferença, Culturas afro-brasileiras em sala de aula; Ideologia racial brasileira na Educação escolar; Escola e diversidade. Disponível em http://www2.unirio.br/unirio/cchs/ educacao/graduacao/pedagogia-presencial/ementario-2/optativas. Acessado em 29/06/2015. 
reduzirem a projetos extracurriculares, tal temática será desvalorizada e continuará sofrendo as pressóes políticas do currículo. Esforços são necessários para que a cultura e a história africana e afro-brasileira estejam representadas oficialmente nos currículos da formação de professores de Música.

É preciso ter a ciência de que, ao disponibilizar uma ou mais disciplinas, sejam elas optativas ou obrigatórias, pautadas na história da cultura africana e afro-brasileira na grade curricular das Licenciaturas em Música, territórios estarão sendo demarcados, o que reforçará fronteiras e desfavorecerá hibridismos - que se compreendem como um conjunto de processos pelos quais as identidades culturais plurais se ressignificam em contato umas com as outras, sem recair em qualquer forma de congelamento ou em uma redução da construçãa de identidades a binarismos como negro/branco, masculino/feminino e erudito/popular (HALL, 1997, 2005; BHABHA, 1998; HICKLING-HUDSON, 2003; PETERS, 2005; CANEN; XAVIER, 2011).

Será que, ao instituir uma disciplina, de forma isolada e sem concatenação com outras, para discutir as relaçôes étnico-raciais, não se está, de certa forma, propagando as cisóes e separaçóes que historicamente foram forjadas socialmente? Acreditamos que tal estratégia possa reforçar preconceitos e discriminaçóes, a despeito de assim não pretender.

Como as questóes étnico-raciais propostas pela Lei $n^{\circ}$ $10.639 / 2003$ devem estar presentes na formação de professores de Música, fugindo de projetos extracurriculares que desvalorizam a temática em questão e de disciplinas isoladas que demarcam territórios e desfavorecem hibridismos? Se sugere que, assim como propóem os Parâmetros Curriculares Nacionais para o ensino fundamental (BRASIL, 1998), a temática da pluralidade cultural, estando inclusas nesta as relaçóes étnico-raciais, fosse tratada como um eixo transversal, ou seja, um assunto que, por sua grande relevância, não pode ser tratado apenas por uma disciplina, mas por diversas disciplinas da grade curricular.

Isso significa que as disciplinas dos cursos de Licenciatura em Música deveriam se adaptar para ministrar os conhecimentos oriundos da cultura negra, o que tange não somente às disciplinas que compóem o grupo dos conhecimentos básicos, mas também àquelas dos grupos de conteúdos específicos e conteúdos teórico-práticos ${ }^{9}$. 
Não é necessário retirar da grade disciplinas que tradicionalmente já são referências nas graduaçóes em Música, como Percepção Musical, Análise Musical e História da Música, mas, como o currículo também é uma seleção da cultura (CANEN; MOREIRA, 2001), nada impede de haver uma nova seleção, a fim de que as musicalidades africana e afro-brasileira possam também transitar nessas e em outras disciplinas.

\section{Considerações finais}

G xpressamos a necessidade de, durante a formaçáo do professor de CMúsica, não nos fixarmos somente em reflexôes e discussões sobre o racismo ou sobre a importância do negro no desenvolvimento social da nação, mas de também incluirmos a musicalidade negra de forma ampla nos repertórios de tal formação, o que corroborará para que o licenciando seja sensibilizado quanto à realidade e à musicalidade de grande parte do alunado que compóe as salas de aula do ensino básico. Embora mudanças curriculares sempre apresentem certo grau de complexidade, advertimos que são necessárias para que a proposta da Lei 10.639 náo seja colocada em prática de forma superficial, mas sim de forma integral e competente.

Defendemos que a metodologia conservatorial que, geralmente, é usada nas Licenciaturas em Música do Brasil (PEREIRA, 2014), deve ceder espaço para que a musicalidade e as próprias formas de ensino de Música tipicamente negras também perpassem o cotidiano da formação de professores de Música, o que poderá resultar em profissionais dotados de conteúdos e técnicas que possibilitarão que estes valorizem a musicalidade negra em suas aulas de Música. Dessa forma, as leis aqui tratadas agirão em conjunto e propiciarão que uma camada significativa de estudantes se veja representada nas aulas de Música.

Acreditamos que um currículo multicultural poderá auxiliar

\footnotetext{
${ }^{9}$ As Diretrizes Curriculares Nacionais para os Cursos de Graduação em Música (2004) dividem as disciplinas em três grandes grupos. Os conteúdos básicos referem-se aos estudos relacionados com a Cultura e as Artes e sāo representados principalmente pelas disciplinas pedagógicas, como Educaçăo e Filosofia, Educaçāo e Sociologia, Currículo etc. Os conteúdos específicos se referem àqueles que desenvolvem a musicalidade do graduando, abrangendo conteúdos relacionados com o Conhecimento Instrumental, Composicional, Estético e de Regência. Por fim, os conteúdos teórico-práticos buscam integrar os conhecimentos teóricos com os práticos, relacionando-os com a área de formação do graduando e, no caso da Licenciatura em Música, seriam ministrados em disciplinas como Didática da Música, Prática de Ensino, Estágio Supervisionado etc.
} 
nesse propósito. Multiculturalismo em Educação pode ser definido como um "campo teórico e político de conhecimentos, que privilegia o múltiplo, o plural, as identidades marginalizadas e silenciadas e que busca formas alternativas para sua incorporação no cotidiano educacional" (CANEN apud BATISTA et al, 2008, p. 213). Um currículo baseado na perspectiva multicultural rejeita hegemonias culturais, buscando incorporar os conhecimentos de grupos que tradicionalmente são excluídos do currículo escolar, indo contra congelamentos identitários e em direção a hibridismos e trocas positivas entre sujeitos diferentes.

Por isso, defendemos que os cursos de Licenciatura em Música abram espaço para a perspectiva multicultural, o que favorecerá não somente professores de Música sensibilizados quanto às questóes dos negros, mas também de todo o alunado que pertence às mais diversas minorias e a outros tipos de identidades estereotipadas, como indígenas, nordestinos e mulheres ${ }^{10}$.

A Música, não só na sala de aula da Educação Básica, mas também no ensino superior e nas pesquisas das pós-graduações, não pode mais estar separada desses tipos de questôes de cunho social, como se as mesmas fossem problemáticas para outras disciplinas. Fenômenos de exclusão, bullyings, xenofobias e outras formas de discriminação acontecem no cotidiano escolar, e o professor de Música deve estar preparado para lidar com eles, atuando positivamente e reprimindo atitudes violentas. Ele também contribuirá fortemente para a questão se tratar desses assuntos no desenrolar das aulas, por meio da sua didática e do currículo da disciplina, e não somente quando situaçóes desagradáveis acontecerem durante as aulas.

\footnotetext{
${ }^{10}$ É notório que a história da Música ocidental é contada por meio de narraçốes de biografias de compositores do sexo masculino. Esse fato, a nosso ver, expressa o caráter machista da sociedade e da academia de Música. Embora existam trabalhos acadêmicos que discutam as relaçóes de gênero na Educaçáo musical e no ensino superior de Música em geral (COHEN, 1987; ANDRADE, 1991; LAMB, 2004; LEONIDO, 2008; CUNHA, 2014), somos da posiçăo de que essa área ainda é pouco contemplada e que se fazem necessários mais trabalhos que busquem resgatar a história das mulheres que contribuíram para o desenvolvimento da Música e da Educação Musical.
} 


\section{Referências}

ALMEIDA, Cristiane Maria Galdino de. Por uma ecologia da formação de professores de música: diversidade e formação na perspectiva de licenciandos de universidades federais do Rio Grande do Sul. 2009. 225 p. Tese (Doutorado em Música) - Universidade Federal do Rio Grande do Sul, 2009.

ANDRADE, Valéria. Notas para um estudo sobre compositoras da música popular brasileira - século XIX. Revista Travessia, Universidade Federal de Santa Catarina, no 23, 1991.

BATISTA, Aline Cleide Batista; SILVA JUNIOR, Paulo Melgaço da; CANEN, Ana. Em busca de um dialogo entre Plano Nacional de Educação (PNE), Formação de professores e multi/interculturalismo. Ensaio: avaliação de políticas públicas em Educação, Rio de Janeiro, v. 21, n. 79, p. 253-267, abr./jun. 2013.

BHABHA, Homi. O Local da Cultura. Belo Horizonte: Editora UFMG, 1998.

BOURDIEU, Pierre; PASSERON, Jean-Claude. A reprodução: elementos para uma teoria do sistema de ensino. Petrópolis: Vozes, 2011.

BRASIL. Diretrizes Curriculares Nacionais dos Cursos de Graduação em Música. Brasília: MEC/SEPPIR, jul. 2004.

. Lei de Diretrizes e Bases da Educação Nacional: no 9394/96. Brasília, 1996.

. Lei 10.639 de 09 de janeiro de 2003. Altera a Lei 9.394, de 20 de dezembro de 1996, que estabelece as diretrizes e bases da educação nacional, para incluir no currículo oficial da Rede de Ensino a obrigatoriedade da temática "História e cultura Afro-Brasileira", e dá outras providências. Brasília, 2003. 
. Lei no 11.769 de 18 de agosto de 2008. Altera a Lei no 9.394, de 20 de dezembro de 1996, Lei de Diretrizes e Bases da Educação, para dispor sobre a obrigatoriedade do ensino da música na educação básica. Brasília, 2008.

CANEN, Ana. Políticas de Formação de Professores: considerações sobre sensibilidades à diversidade cultural. Revista da Educação Pública. Cuiabá, v. 20, n. 43, p. 253-265, maio/agosto 2011.

.; MOREIRA, Antônio Flávio Barbosa. Reflexôes sobre multiculturalismo na escola e na formação docente. In CANEN, Ana; MOREIRA, Antônio Flávio Barbosa. Ênfases e omissóes no currículo. Campinas: Papirus Editora, 2001.

.; XAVIER, Giseli Pereli de Moura. Formação continuada de professores para a diversidade cultural: ênfases, silêncios e perspectivas. Revista Brasileira de Educação. v. 16 n. 48 set.-dez. 2011.

COHEN, A. International Encyclopedia of Women Composers. Books \& Music: New York, 1987.

CONSERVATÓRIO BRASILEIRO DE MÚSICA - CENTRO UNIVERSITÁRIO. Projeto Político-Pedagógico do curso de Licenciatura em Música. Rio de Janeiro, 2011.

CUNHA, Laura Cardoso. Feminaria Musical II: O que (não) se produz sobre música e mulheres no Brasil nos Anais dos encontros das associaçóes musicais brasileiras. In. Anais da $18^{a}$ REDOR, Universidade Federal de Pernambuco, Recife - PE, 2014.

GREIF, Elza Lancman. Ensinar e aprender música: o Bandão no caso Escola Portátil de Música. Tese. (Doutorado em Música) - Programa de Pós-Graduação em Música, 2007.

A aprendizagem musical no bandão da escola portátil de Música. In. Anais do XI Colóquio de Pós-Graduação em Música da UNIRIO, 2006. 
HALL, Stuart. A identidade cultural na pós-modernidade. 10a ed. Rio de janeiro: dp\&a; 2005.

- Da diáspora: identidades e mediaçóes culturais. Belo Horizonte: Editora da UFMG, 2003.

HICKLING-HUDSON, Anne. Multicultural Education and the Postcolonial Turn. Policy Futures in Education, 381 -401, 2003.

LAMB, Roberta. Aria Senza Accompagnamento: A woman behind the theory. Gender, Education, Music and Society Journal, Volume IV, Number 4, 2004.

LAZZARIN, Luís Fernando. Multiculturalismo e multiculturalidade: recorrências discursivas na educação musical. Revista da ABEM, Porto Alegre, V. 19, 121-128, mar. 2008.

LEHER, Roberto. Wolfowitz no Banco Mundial: educação como segurança. Experiências de educaçáo popular, disponível em www. outrobrasil.net.

LEONIDO, Levi. Composição Musical de gênero feminino. Revista Sinfonia Virtual, número 09, 2008, disponível em http:// www.sinfoniavirtual.com/revista/009/comosicao_musical_genero_ femenino.php.

MATEIRO, Teresa. Uma análise de projetos pedagógicos de licenciatura em música. Revista da ABEM, Porto Alegre, V. 22, 57-66, set. 2009.

PEREIRA, Marcus Vinícius Medeiros. Licenciatura em música e habitus conservatorial: analisando o currículo. Revista da ABEM. Londrina, v.22, n. 32, p. 90-103, jan/jun. 2014.

PETERS, Michael. Education, Post-structuralism and the Politics of Difference. Policy Futures in Education, Volume 3, Number 4, 2005.

PIRES, Nair. A identidade das licenciaturas na área de música: multiplicidade e hierarquia. Revista da ABEM, Porto Alegre, V. 9, 81- 
88, set. 2003.

SANTOS, Regina Marcia Simão dos; DIDIER, Adriana Rodrigues; VIEIRA, Eliane Maria; ALFONZO, Neila Ruiz. Pensar música, cultura e educação hoje. In: SANTOS, Regina Márcia Simão (org.). Música, Cultura e Educação: Os múltiplos espaços de educação musical. Porto Alegre: Sulina, 2012.

SILVA, Tomaz Tadeu da. Documentos de Identidade: Uma introdução às teorias do Currículo. Autêntica: Belo Horizonte, 2009.

SOBREIRA, Silvia Garcia. Disciplinalização da música e produção de sentidos sobre educação musical: investigando o papel da ABEM no contexto da Lei no 11.769/2008. Tese (doutorado) - Universidade Federal do Rio de Janeiro, Faculdade de Educação, 2012.

SOUZA, Maria Elena Viana. Relaçóes raciais e educação: desafios e possibilidades para a formação continuada do professor. Revista da Educação Pública. Cuiabá v. 21 n. 46 p. 289-301 maio/ago. 2012.

UNIVERSIDADE FEDERAL DO RIO DE JANEIRO. Projeto Político-Pedagógico do curso de Licenciatura em Música da Escola de Música da Universidade Federal do Rio de Janeiro. Rio de Janeiro, 2008. Disponível em http://www.musica.ufrj.br/index. php?option=com_content $\&$ view=article $\&$ id $=142 \&$ Itemid $=84$

UNIVERSIDADE FEDERAL DO ESTADO DO RIO DE JANEIRO. Licenciatura em Música do Instituto Villa-Lobos da Universidade Federal do Estado do Rio de Janeiro. Rio de Janeiro, 2006. Disponível em http://www2.unirio.br/unirio/cla/ivl/cursos/ graduacao/licenciatura-em-musica/licenciatura_projeto_pedagogico_ ivl_unirio.pdf

VIEIRA, Lia Braga. A construção do professor de música: o modelo conservatorial na formação e atuação do professor de música em Belém do Pará. Tese (Doutorado) - Universidade Estadual de Campinas, Faculdade de Educação. Campinas, SP, 2000. 